


\title{
Green Synthesis of Antioxidant Silver and Platinum Nanoparticles Using Ginger and Turmeric Extracts and Investigation of Their Catalytic Activity
}

\author{
Muradiye SAHIN ${ }^{*} \mathbb{D}$, Ilkay Hilal GUBBUK ${ }^{2}$ \\ 1-Graduate School of Natural Sciences, Selcuk University, 42003, Selcuklu/Konya,Turkey \\ 2- Department of Chemistry, Selcuk University, Campus, 42075, Konya, Turkey
}

Abstract: Antioxidant silver nanoparticles (AgNPs) and platinum nanoparticles (PtNPs) were synthesized by using ginger and turmeric extracts with green method in this work. Thus these nanoparticles synthesized were characterized by UV-Vis spectroscopy, SEM-EDX and FTIR. The UV-Visible spectra of the AgNPs revealed a characteristic surface plasmon resonance peak at 420-425 nm and the UV-Visible spectra of the PtNPs revealed a characteristic surface plasmon resonance peak at 234-240 nm. The synthesized AgNPs and PtNPs acted as a catalyst to the degradation of dyes (rhodamine B, methyl orange, and methylene blue) with sodium borohydride $\left(\mathrm{NaBH}_{4}\right)$. Green synthesized antioxidant silver nanoparticles effectively degraded the dyes nearly 4-10 min. and green synthesized antioxidant platinum nanoparticles effectively degraded the dyes nearly 15-24 min. of exposure time.

Keywords: Platinum nanoparticles, catalysis, silver nanoparticles, antioxidants, dyes.

Submitted: December 14, 2018. Accepted: April 06, 2019.

Cite this: Şahin M, Gubbuk I. Green Synthesis of Antioxidant Silver and Platinum Nanoparticles Using Ginger and Turmeric Extracts and Investigation of Their Catalytic Activity. JOTCSA. 2019;6(3):403-10.

DOI: https://doi.org/10.18596/jotcsa.497440.

${ }^{*}$ Corresponding author. E-mail: muradiyeok 40@hotmail.com.

\section{INTRODUCTION}

Noble metal nanoparticles such as silver and platinum have emerged as promising antimicrobial agents and catalytic elements so have been greatly applied in the cosmetic, medical, textile and food industries (1). Catalysts of metal nanoparticles such as silver are efficient for various reactions. Silver have earned significant caution due to their inimitable electronic properties and high Fermi potential (2, 3).

Over the last few years, herb-welded biologically synthesis of the nanoparticles are earned overage significance because of their inexpensive and environmentally approach (4-7). The applications of AgNPs and PtNPs in medicine, optoelectronics, optics, and catalysis are well known and has received great attention due to the surface strong absorption in the visible region which can be easily monitored by UV-visible spectrophotometer (8). Moreover, these NPs have been gaining significant research interest due to their unique shape and size-dependent optical, antimicrobial and catalytic properties (9).

In this work, silver and platinum nanoparticles are synthesized, for the first time, using ginger and turmeric antioxidant extracts as a reducing agent for the first time. Antioxidants limit the deleterious effects of oxidative reactions so they can involve scavenging free radicals followed by the stabilization of nanoparticles.

Organic dyes are a major class environmental pollutant in various industries, particularly textiles. The organic dyes can cause many 
diseases such as blood diseases, cancer, renal and hepatic damage for living beings (10). These dyes generate tons of wastewater. Clean and usable water is a prerequisite for life. Nanoparticles provide remediation and treatment in water (11). In order to remove dyes such as methyl orange (MO), methylene blue (MB) and rhodamine $B$ (RB) faster from water, catalytic potential role of the synthesized AgNPs and PtNPs' in the in the presence of sodium borohydride $\left(\mathrm{NaBH}_{4}\right)$ is investigated in this study.

\section{EXPERIMENTAL SECTION}

\section{Preparation of the extract}

Ginger and turmeric powders were purchased from the haberdasher. To obtain ginger and turmeric extracts, $1 \mathrm{~g}$ of the particular powder was added to $50 \mathrm{~mL}$ of distilled water. The mixture was stirred continuously at $25^{\circ} \mathrm{C}$ for 5 hours. After grinding, the solution was filtered through a filter paper. Then all extracts were stored at room temperature to be used for biosynthesis of silver and platinum nanoparticles from silver nitrate or chloroplatinic acid.

\section{Synthesis of silver and platinum nanoparticles}

In order to investigate the effect of antioxidant extracts on the synthesis of AgNPs and PtNPs, each extract was mixed with silver nitrate $\left(\mathrm{AgNO}_{3}\right)$ or chloroplatinic acid $\left(\mathrm{H}_{2}\left[\mathrm{PtCl}_{6}\right] . \mathrm{H}_{2} \mathrm{O}\right)$. Each extract $(7 \mathrm{~mL})$ was added to $0.01 \mathrm{M} 50 \mathrm{~mL}$ of $\mathrm{AgNO}_{3}$ or $\left(\mathrm{H}_{2}\left[\mathrm{PtCl}_{6}\right] \cdot \mathrm{H}_{2} \mathrm{O}\right)$. The solutions were left at room temperature under magnetic stirring for the completion of the synthesis. Reduction of silver ions $\left(\mathrm{Ag}^{+}\right)$to silver $\left(\mathrm{Ag}^{\circ}\right)$ was completed around 3-5 $\mathrm{min}$. and formation of nanoparticles was visually identified by color change and followed the UV-Vis spectral analysis. Reduction of platinum ions $\left(\mathrm{Pt}^{4+}\right)$ to platinum $\left(\mathrm{Pt}^{0}\right)$ was completed around 12-15 min. and was followed by the color change of the solution from yellow to brownish-yellow to deep black.

\section{Catalytic study}

The reduction of methyl orange (MO), methylene blue (MB) and rhodamine $B$ (RB) by sodium borohydride $\left(\mathrm{NaBH}_{4}\right)$ in the existence of each AgNPs and each PtNPs as a heterogeneous catalyst at $25{ }^{\circ} \mathrm{C}$ was conducted. $1 \mathrm{~mL}$ of the $\mathrm{NaBH}_{4}$ solution $\left(1 \otimes 10^{-2} \mathrm{~mol} \mathrm{~L} \mathrm{~L}^{-1}\right.$ ) is mixed with 1 $\mathrm{mL}$ of dyes $\left(1 \otimes 10^{-5} \mathrm{mg} \mathrm{L}^{-1}\right) .0 .5 \mathrm{~mL}$ antioxidant silver or platinum nanoparticles was added to this mixture and then the UV-VIS spectra have been recorded at regular intervals of time. The degradation of all dyes are shown by the decolorization of the solution to colorless. The concentrations of the MO, RB and MB dyes were quantified by measuring the absorption band at 465,564 and $664 \mathrm{~nm}$, respectively.

\section{RESULT AND DISCUSSION}

\section{Characterization}

Silver and platinum nanoparticles fabricated from ginger and turmeric extracts as a reducting agent have been examined for their heterogeneous catalytic activity reaction. The reduction of both extract metal ion solutions was quantitative and identified by a change in color from yellow to brown and orange to dark brown for ginger and turmeric respectively. The phenols and the other compounds in the antioxidant extracts provide in efficient reduction of silver and platinum salts to nanoparticles $(12,13)$. Figure 1 showed that the UV visible spectra of the AgNPs revealed a characteristic surface plasmon resonance peak at 420-425 $\mathrm{nm}$ and the UV-Visible spectra of the PtNPs revealed a characteristic surface plasmon resonance peak at $234-240 \mathrm{~nm}$.
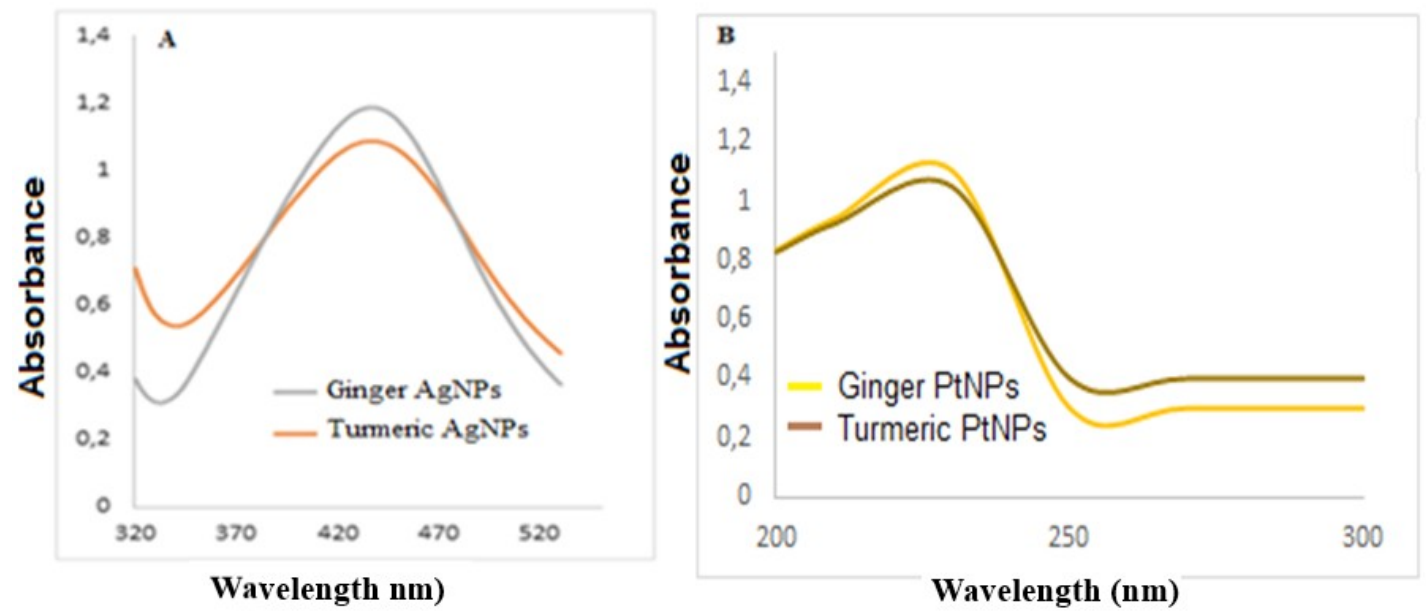

Figure 1. UV-Vis. spectra of A) AgNPs and B) PtNPs. 
The FTIR spectra of ginger silver nanoparticles (Gng-AgNPs) and turmeric silver nanoparticles (Trm-AgNPs) were shown in Figure 2. The bands at $1566 \mathrm{~cm}^{-1}$ proved that $\mathrm{C}=\mathrm{C}$ double bond or aromatic annulus or $\mathrm{C}=\mathrm{O}$ carboxyl groups. The bands at $1026 \mathrm{~cm}^{-1}$ proved that $-\mathrm{CN}$ - amine groups. The IR bands at $1307 \mathrm{~cm}^{-1}$ proved the presence of geminal methyl (14-16).

The FTIR spectra of ginger platinum nanoparticles (Gng-PtNPs) and turmeric platinum nanoparticles (Trm-PtNPs) were shown in Figure 3.

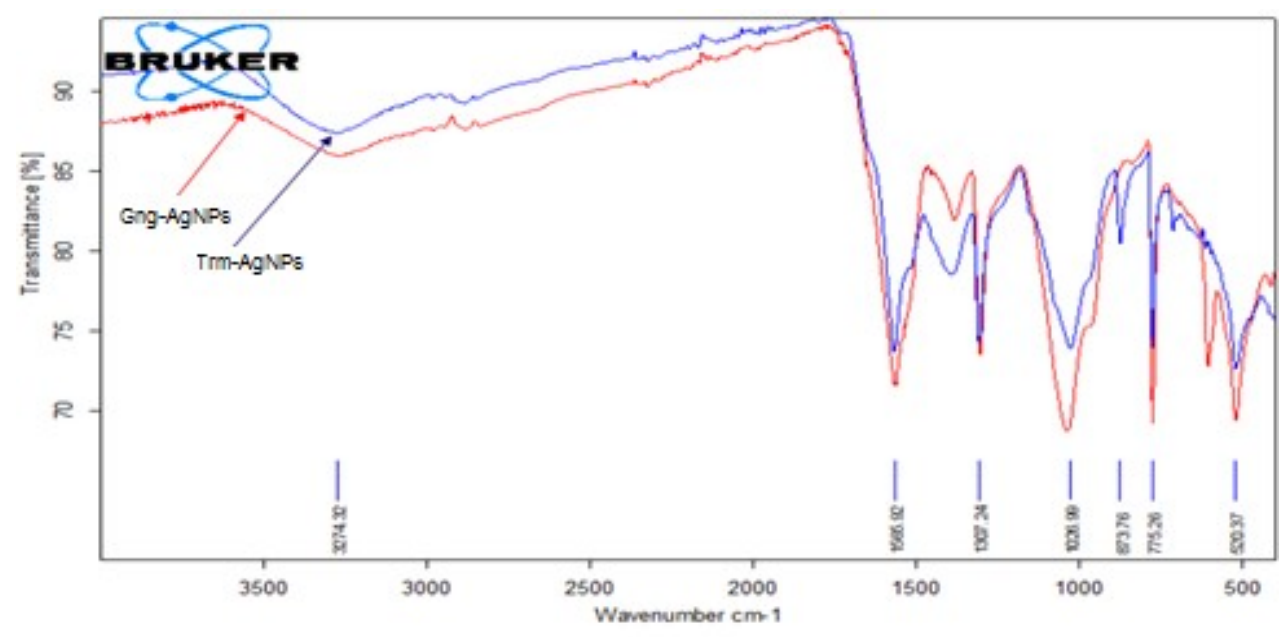

Figure 2. ATR-FTIR spectra of Gng-AgNPs (red line) and Trm-AgNPs (blue line).

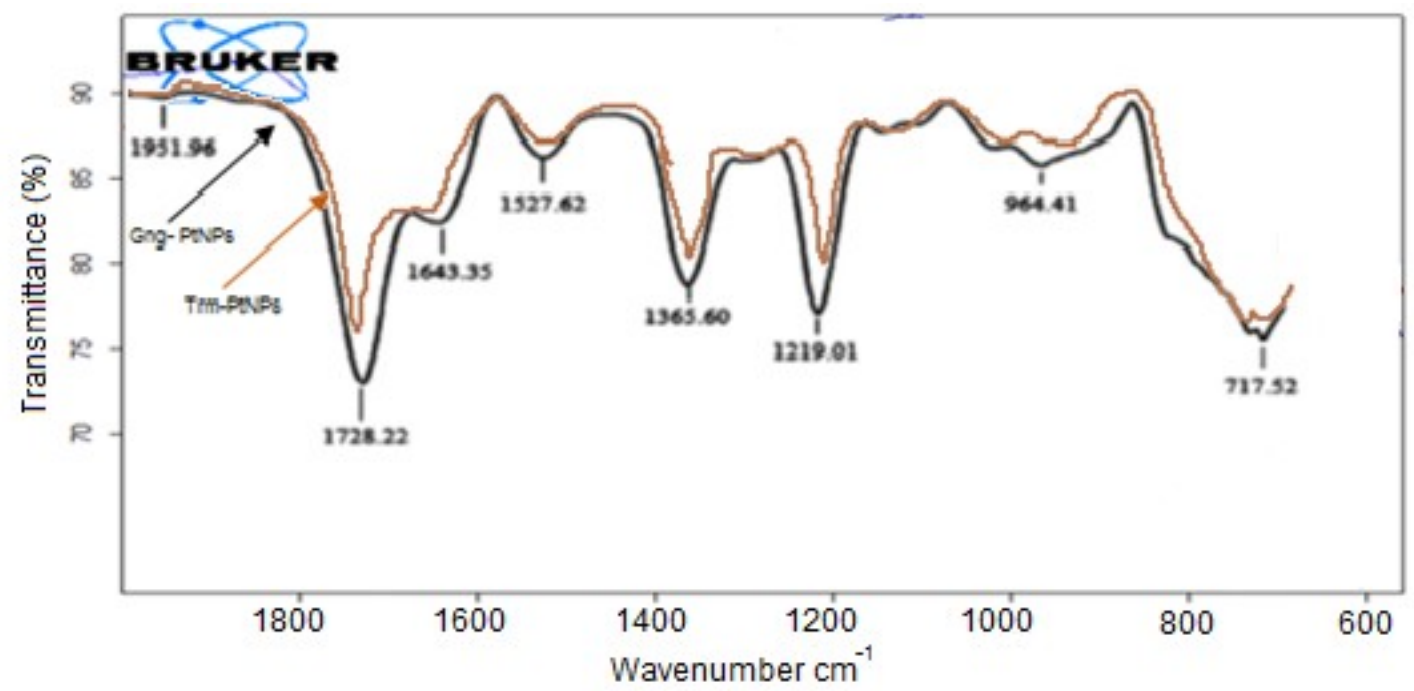

Figure 3. ATR-FTIR spectra of Gng-PtNPs (black line) and Trm-PtNPs (brown line).

The crystalline nature of the silver nanoparticles was confirmed by SEM and EDX pattern as shown in Figure 4. Also, elemental analysis was obtained using the SEM-EDX combination. An EDX spectroscopy was used to approve the existence of silver nanoparticle. The EDX view evidently confirmed the existence of silver nanoparticles by demonstration of a violent spectra within fundamental elements. Ag, Mg, Al, Fe etc. were observed in the EDX analysis samples which were concluded that these could be caused by antioxidant extract. 



Figure 4. SEM images and EDX results of Gng-AgNPs (a) and Trm-AgNPs (b).

\section{Catalytic study}

The reduction of methyl orange (MO), Rhodamine $B$ (RB) and methylene blue (MB) by sodium borohydride $\left(\mathrm{NaBH}_{4}\right)$ in the existence of each AgNPs or each PtNPs as a heterogeneous catalyst at $25{ }^{\circ} \mathrm{C}$ was conducted. $1 \mathrm{~mL}$ of $\mathrm{NaBH}_{4}$ solution $\left(1 \times 10^{-2} \mathrm{~mol} \mathrm{~L}^{-1}\right)$ is mixed with $1 \mathrm{~mL}$ of dyes $\left(1 \times 10^{-5} \mathrm{mg} \mathrm{L}^{-1}\right) .0 .5 \mathrm{~mL}$ antioxidant silver or platinum nanoparticles was added to this mixture and then the UV-Vis spectra have been recorded at regular intervals of time. The degradation of all dyes are shown by the decolorization of the solution to colorless.
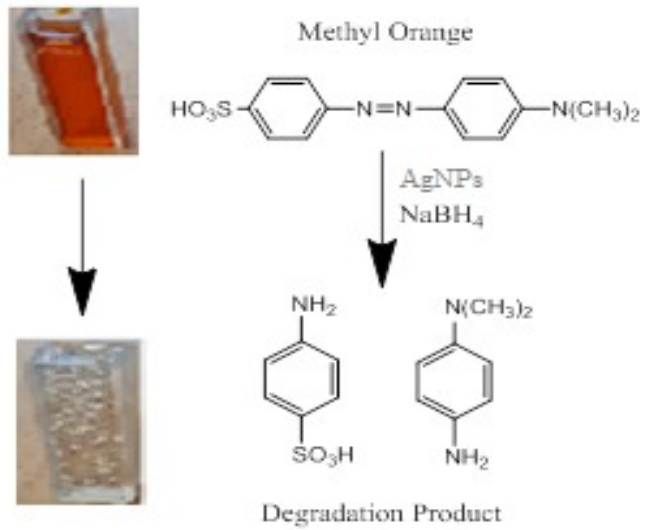

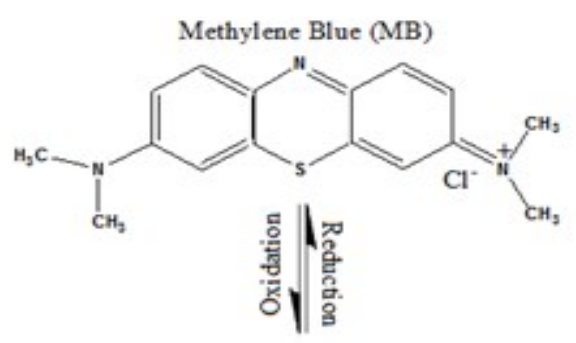<smiles></smiles>
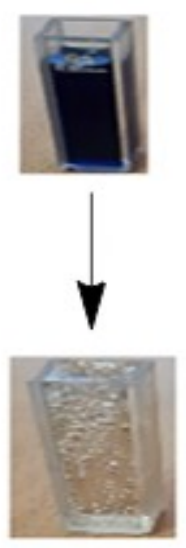

Figure 5. Degradation mechanism of the $M B$ and $M O$ and color change.

All dyes can be reduced by both nanoparticles to nontoxic species and the reduction rate is very fast. Antioxidant silver nanoparticles with higher catalytic activity than platinum nanoparticles can speed up the reduction rate of dyes, thus increasing the degradation capacity. 
Şahin M, Gubbuk HI. JOTCSA. 2019; 6(3): 403-410.
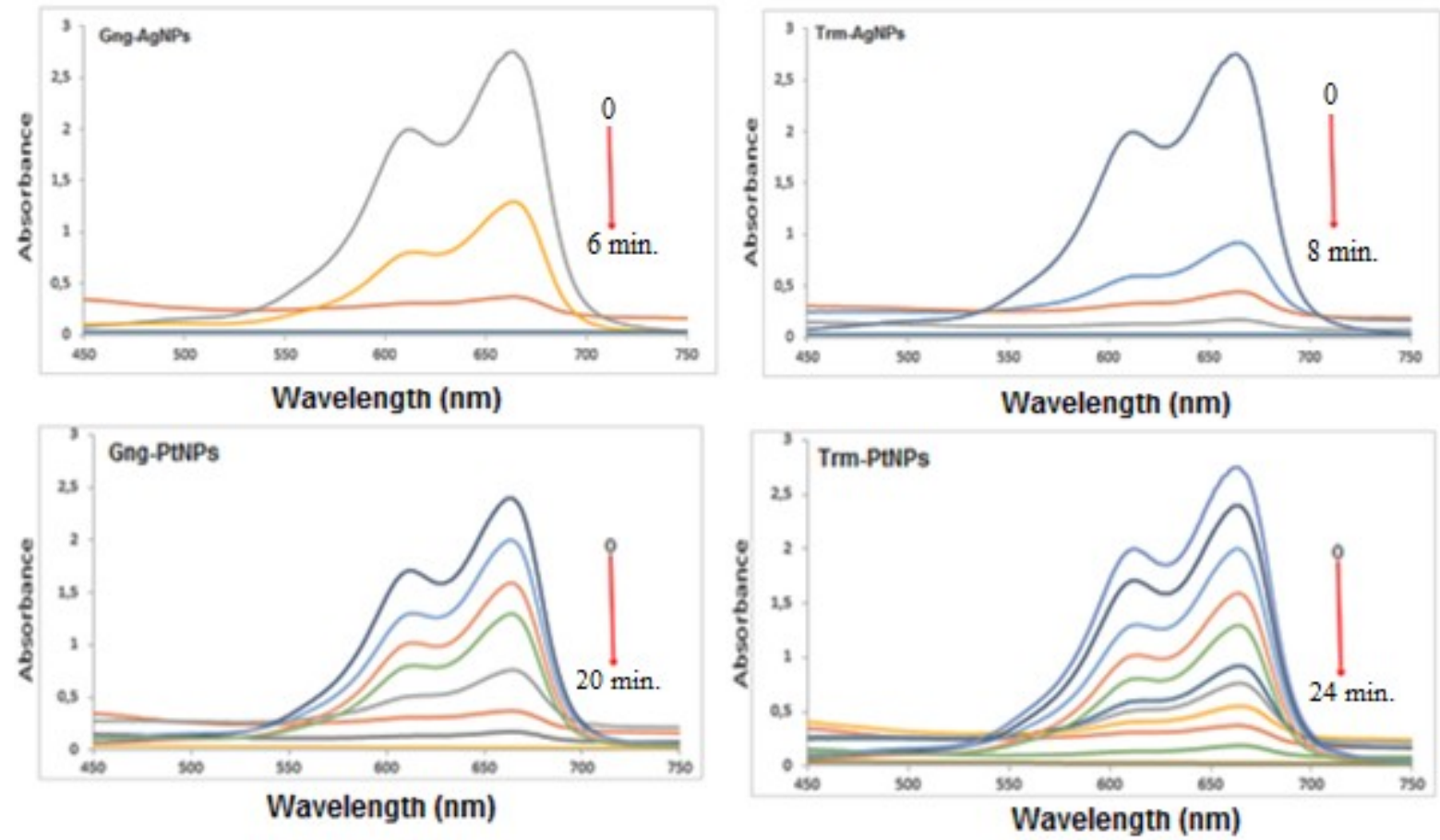

Figure 6. UV-Vis. spectra of the catalytic reduction of Methylene Blue.
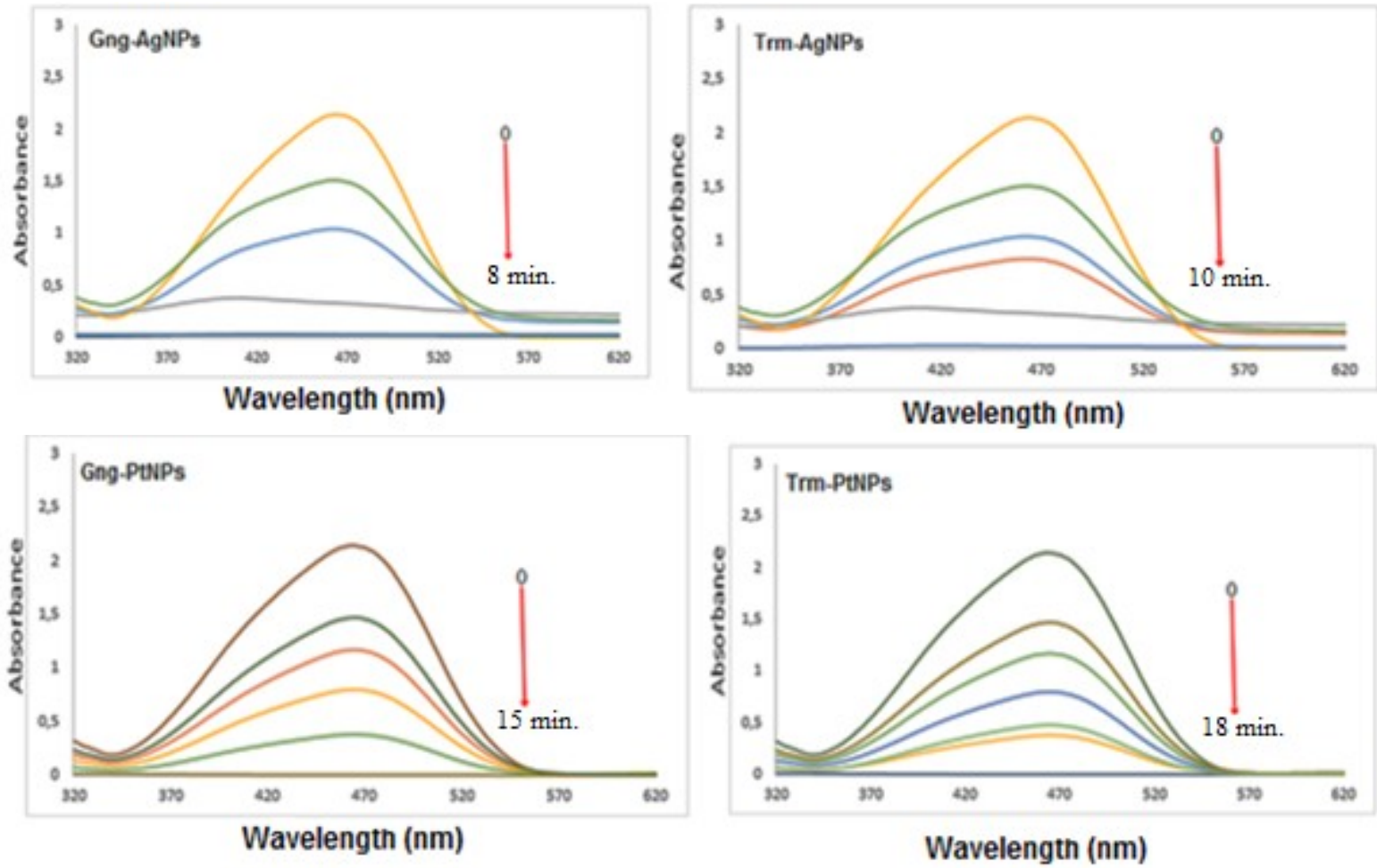

Figure 7. UV-Vis. spectra of the catalytic reduction of Methyl Orange. 


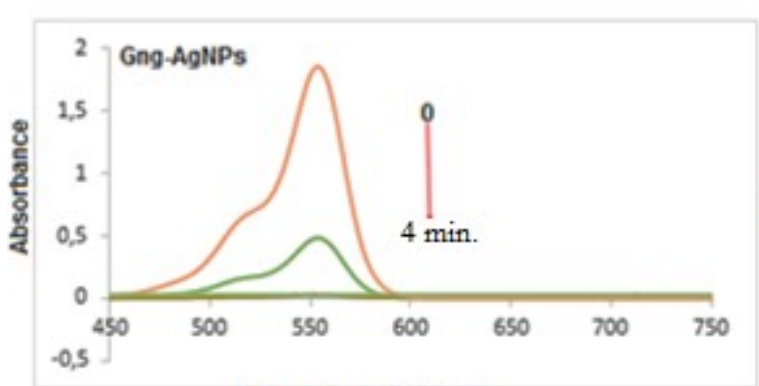

Wavelength $(\mathrm{nm})$

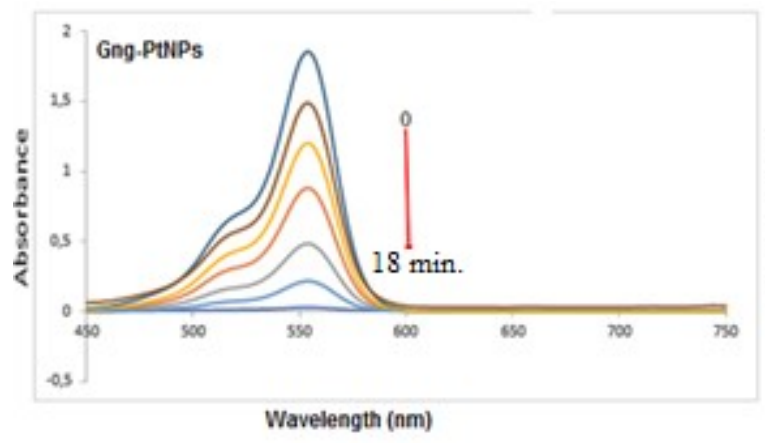

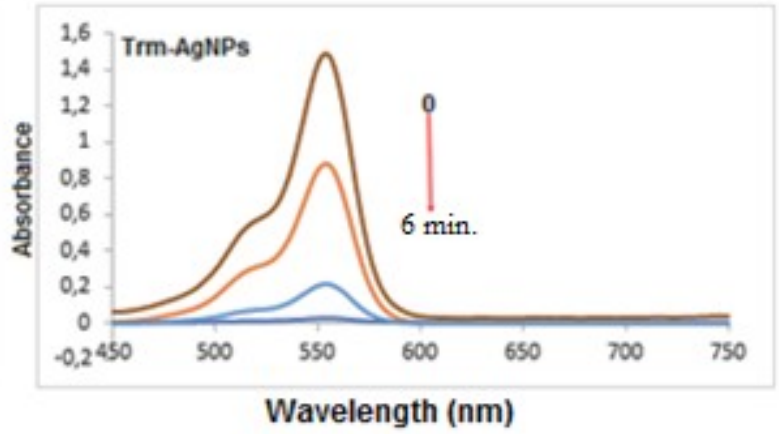

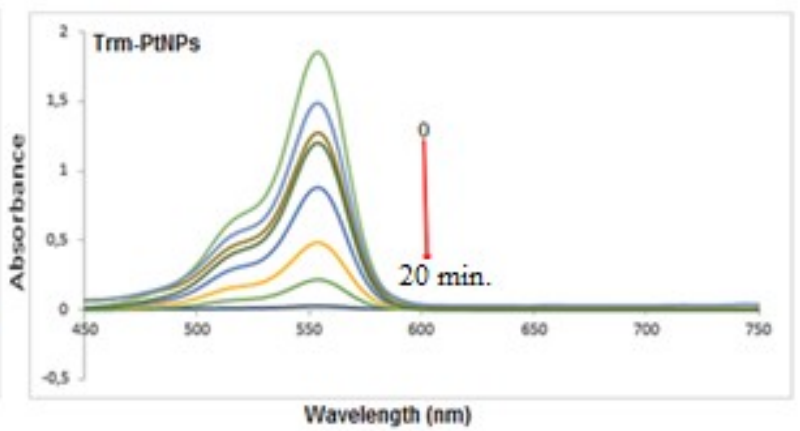

Figure 8. UV-Vis. spectra of the catalytic reduction of Rhodamine B.

\section{CONCLUSION}

Antioxidant silver and platinum nanoparticles were prepared successfully via a facile, simple, economic, and eco-friendly route from ginger and turmeric extracts. The UV-Vis, FTIR, SEM, EDX spectroscopic analyses confirmed the formation of nanoparticles. The catalytic feature of the Gng-AgNPs, Gng-PtNPs, Trm-AgNPs and TrmPtNPs in degrading $\mathrm{RB}, \mathrm{MB}$ and $\mathrm{MO}$ to their end products in the presence of $\mathrm{NaBH}_{4}$ at room temperature were studied.

Antioxidant silver and platinum nanoparticles in the existence of $\mathrm{NaBH}_{4}$ catalyze the degradation reaction, which leads to the removal of $\mathrm{RB}, \mathrm{MB}$ and MO. Absorbance became almost zero in the case of all of dyes. Thus Gng-AgNPs Gng-PtNPs, Trm-AgNPs and Trm-PtNPs provided a good electron transfer that catalyzes the reactions by reducing the activation energy. Also, as a reducing agent, $\mathrm{NaBH}_{4}$, was not capable to reduce $\mathrm{RB}, \mathrm{MB}$ and $\mathrm{MO}$ in absence of a catalyst, indicating the efficacy of Cnm-AgNPs Gng-PtNPs, Trm-AgNPs and Trm-PtNPs. Therefore, it was concluded that antioxidant silver and platinum nanoparticles significantly reduce the color of $\mathrm{RB}$, $\mathrm{MB}$ and $\mathrm{MO}$ dyes in the existence of $\mathrm{NaBH}_{4}$, but antioxidant silver nanoparticles with higher catalytic activity than platinum nanoparticles can speed up the reduction rate of dyes, thus increasing the degradation capacity.

\section{REFERENCES}

1. Shao $\mathrm{Y}, \mathrm{Wu} \mathrm{CH}, \mathrm{Wu} \mathrm{TT}$, Yuan $\mathrm{CH}$, Chen SG, Ding $T$, et al. Green synthesis of sodium alginatesilver nanoparticles and their antibacterial activity. Int J Biol Macromol. 2018;111:1281-92.

2. Sintubin L, De Windt W, Dick J, Mast J, van der Ha D, Verstraete W, et al. Lactic acid bacteria as reducing and capping agent for the fast and efficient production of silver nanoparticles. Appl Microbiol Biot. 2009;84(4):741-9.

3. Wang MM, Zhang WJ, Zheng XS, Zhu PZ. Antibacterial and catalytic activities of biosynthesized silver nanoparticles prepared by using an aqueous extract of green coffee bean as a reducing agent. Rsc Adv. 2017;7(20):12144-9.

4. Raja S, Ramesh V, Thivaharan V. Green biosynthesis of silver nanoparticles using Calliandra haematocephala leaf extract, their antibacterial activity and hydrogen peroxide sensing capability. Arabian J. Chem. 2017; 10:253-61.

5. Padalia $H$, Moteriya $P$, Chanda S. Green synthesis of silver nanoparticles from marigold flower and its synergistic antimicrobial potential. Arabian J. Chem. 2015;8: 732-41.

6. Velayutham K, Rahuman AA, Rajakumar G, Roopan SM, Elango G, Kamaraj C, Marimuthu S, SanthoshKumar T, Iyappan M, Siva C. Larvicidal activity of green synthesized silver nanoparticles using bark aqueous extract of Ficus racemosa 
against Culex quinquefasciatus and Culex gelidus. Asian Pac. J. Trop. Med. 2013;6:95-101.

7. Kumar DA, Palanichamy V, Roopan SM. Green synthesis of silver nanoparticles using Alternanthera dentata leaf extract at room temperature and their antimicrobial activity. Spectrochim. Acta A 2014;127:168-171.

8. Edison TJI, Sethuraman MG. Instant green synthesis of silver nanoparticles using Terminalia chebula fruit extract and evaluation of their catalytic activity on reduction of methylene blue. Process Biochemistry 2012;47:1351-7.

9. Baruah B, Gabriel GJ, Akbashev MJ, Booher ME. Facile Synthesis of Silver Nanoparticles Stabilized by Cationic Polynorbornenes and Their Catalytic Activity in 4 Nitrophenol Reduction. Langmuir 2013;29:4225-30.

10. Veisi $H$, Azizi S, Mohammadi P. Green synthesis of the silver nanoparticles mediated by Thymbra spicata extract and its application as a heterogeneous and recyclable nanocatalyst for catalytic reduction of a variety of dyes in water. J Clean Prod. 2018;170:1536-43.

11. Sowmyya T, Lakshmi GV. Antimicrobial and Catalytic Potential of Soymida febrifuga Aqueous
Fruit Extract-Engineered Silver Nanoparticles. Bionanoscience. 2018;8:179-95.

12. Harborn, JB. Introduction to Ecological Biochemistry, 3rd ed. London Academic Press. $1988 ; 356$.

13. Vidhu VK, Philip D. Catalytic degradation of organic dyes using biosynthesized silvernanoparticles. Micron 56. 2014;54-62.

14. Lopez-Miranda JL, Vazquez $M$, Fletes $N$, Esparza R, Rosas G. Biosynthesis of silver nanoparticles using a Tamarix gallica leaf extract and their antibacterial activity. Mater. Lett. 2016;176:285-9.

15. Karimzadeh I, Aghazadeh M, Ganjali MR, Norouzi P, Shirvani-Arani $S$, et al. A novel method for preparation of bare and poly(vinylpyrrolidone) coated superparamagnetic iron oxide nanoparticles for biomedical applications, Mater. Lett. 2016;179:5-8.

16. Khan ZUH, Khan $A$, Shah $A$, Wan $P$, Chen $Y$, et al. Enhanced photocatalytic and electrocatalytic applications of green synthesized silver nanoparticles, J. Mol. Liq. 2016;220:24857. 
